\title{
Tensions in sustainable warehousing: including the blue-collar perspective on automation and ergonomic workplace design
}

\author{
Tim Gruchmann ${ }^{1}$ (D) Annika Mies $^{2}$ (D) Thomas Neukirchen $^{3}$ (D) \\ Stefan Gold ${ }^{2}$ (i)
}

Published online: 14 May 2020

(c) The Author(s) 2020

\begin{abstract}
In many industrial countries, demographic changes towards an aging society go hand in hand with the need for ergonomic workplaces. Therefore, it is necessary to rethink workplace designs and work processes, particularly in industrial professions, such as logistics. As logistics activities are still characterized by a high amount of manual effort, they represent a suitable field for gaining empirical insights into the implementation of automation and ergonomic practices to inform social sustainable warehousing logistics strategies. By assuming a paradox perspective, this study accordingly examines the research question to which extent tensions arise in the context of sustainable warehousing regarding the implementation of technical automation and improved ergonomic processes. To answer this question, automation and ergonomics practices are studied at two logistics service providers and an industrial manufacturer in Germany. By applying a mixed-methods approach, the study analyzes empirical data derived from semi-structured interviews with logistics and human resource managers at four warehouse sites of these companies. Besides identifying relevant criteria and paradoxical tensions in improving handling processes in the specific cases, technology alternatives were evaluated from blue-collar employees' perspectives using an analytic hierarchy process (AHP) survey. The present study provides evidence that paradoxical tensions with regard to belonging and performing, as well as between organizational levels and through the change process itself are most important in this context. In this line, the current study contributes to theory and practice by providing insights into paradoxical tensions in warehousing logistics and discussing how automation and ergonomic transformational processes can be successfully managed through addressing interrelated demands of blue-collar workers, managers, and customers.
\end{abstract}

Annika Mies

mies@uni-kassel.de

Extended author information available on the last page of the article 
Keywords Warehousing logistics · Automation · Ergonomics · Sustainability tensions · Human-technology interaction $\cdot$ Sustainable transformation

JEL Classification L23 · M11 · M54 · O33

\section{Introduction}

The working environment will be increasingly affected by changes in demographics in the following years. The proportion of the population of working age will decline, while the average age of the workforce will continue to rise (Schaffer et al. 2012). This demographic development will likely lead to a shortage of skilled workers and young employees across all sectors (Bogataj et al. 2019). The logistics sector has already been affected by a shortage of skilled labor. In addition, employees working in logistics professions have a high risk of suffering from musculoskeletal disorders (MSDs), as these occupations are often labor-intensive and have repetitive motions (Grosse et al. 2015). This risk is up to 75\% higher than the European Union average over all professions (Schneider and Irastorza 2010). Accordingly, technical automation and improved ergonomic designs are relevant for employee well-being and health and safety, thereby supporting socially sustainable development in the logistics sector. The economic effects of advanced workplace designs must not be neglected either. Cost considerations include not only those costs related to the implementation of such measures but also possible payoffs in the form of labor cost reductions and productivity increases (Hendrick 2003; Vink et al. 2006). In this context, a positive relationship between economic productivity and occupational health and safety through investments in ergonomic design and automation technology has already been shown (Neumann et al. 2006; Das et al. 2008). Thus, it is somewhat surprising that intralogistics activities are still characterized by mainly manual tasks (Otto et al. 2017; Schneider et al. 2019).

In a broader context, Carter et al. (2019) label working conditions as promising future research fields in sustainable supply chain management. Indeed, the dependence on other supply chain members as well as fierce competition in the sector affect the implementation of socially sustainable practices, particularly when spatial distance increases (Hoejmose et al. 2013; Gruchmann and Seuring 2018). This scattered picture of potential benefits of workplace improvements for employees and employers on the one side, and the actual delay in its implementation on the other hand, in particular in the logistics sector, calls for additional research shedding light onto these inconsistencies and contradictions. In fact, improved workplace design requires the acceptance among all involved stakeholder groups, particularly among blue-collar workers, in order to yield high levels of health and safety. Particularly safety practices are often managed separately due to contradictory stakeholder demands (Pagell et al. 2014). This might lead to the prioritization of production goals over safety performance as a reaction to an external environment pushing for lower costs and faster production. We respond to this need by scrutinizing the challenges of implementing sustainable warehousing through the angle of a paradox perspective (Hahn et al. 2015, 2018). Accordingly, the following research question guided this study: What tensions arise in the context of 
sustainable warehousing regarding the implementation of technical automation and improved ergonomic processes?

Tensions refer to related but contradictory demands that may exist in the context of present and future objectives or regarding the competing elements of economic, societal, and environmental sustainability (Slawinski and Bansal 2012). Building on the integrative logic of paradox theory, these conflicting demands are regarded as paradoxical when they represent "contradictory yet interrelated elements that exist simultaneously and persist over time” (Smith and Lewis 2011, p 382). So far, the analysis of sustainability-related issues is rather dominated by instrumental foci, such as the win-win or trade-off paradigms (Matthews et al. 2016; Maas et al. 2018), while only a few researchers have empirically studied sustainability tensions in operations and supply chain management (OSCM) from a paradox perspective (Sandberg 2017). Although sustainable logistics strategies often lead to a win-win situation between economic and environmental goals (e.g., through cleaner technologies), or require trade-offs between economic and social performance (e.g., through higher wages), such an instrumental perspective leaves little room for radical shifts in business practices (Hahn et al. 2018) as it restricts strategic options to those that can be immediately connected to a profit logic. In contrast, the integrative paradox approach to tensions embraces the multi-directional relationships within and between the organization and the system as well as the interrelatedness and complexity of sustainability (Slawinski and Bansal 2012). Paradox theory, furthermore, suggests iterative or cyclical actions, such as continuous improvement processes, that may transform a situation in such a way that interrelated demands can be pursued simultaneously without necessarily having to resolve the actual tension (Smith and Lewis 2011).

In this way, we generally respond to Van der Byl and Slawinski's (2015) call for more empirical research addressing sustainability paradoxes. Acknowledging the actions required for meeting contradictory demands between human labor and machine autonomy, the present study also connects to the literature in terms of human-machine or human-technology interaction, which is utilized to discuss further sustainability transformations in warehousing logistics (cf. Szalma 2009; Klumpp and Zijm 2019). Thus, the present study contributes to theory and practice by investigating paradoxical tensions in warehousing logistics and discussing how automation and ergonomic transformational processes can be successfully managed through addressing interrelated demands in this field.

The remainder of this paper is structured as follows: In Sect. 2, the relevant literature on sustainable warehousing practices, as well as on corporate sustainability tensions and paradox theory, is concisely presented. In Sect. 3, the research design is described. In Sects. 4 and 5, the findings of the multiple case study are reported, and compared with those of the analytic hierarchy process (AHP) survey. In Sect. 6, the findings are discussed, while in Sect. 7, the paper is concluded, and recommendations for future research directions are provided. 


\section{Literature review}

\subsection{Ergonomics and automation practices in sustainable warehousing}

The need for an ergonomic workplace design has been recognized in academic research and business practice and has gained growing attention in recent years. Ergonomics, in this context, is understood as science linking human and automated work, the core objective of which is to optimize working conditions, while taking human abilities and performance limitations into account (Vink et al. 2006). Ergonomic workplace design is particularly important for repetitive work, tasks that involve frequent lifting and lowering motions, and jobs involving heavy load handling (Grosse et al. 2015; Otto et al. 2017). The overall aim of ergonomic workplace design is to align the work process with the human physique and psyche (Conti et al. 2006), as well as to optimally design the arrangement of work pieces and tools in production and logistics. Therefore, rather than applying a technology-centered workplace design, applying a humancentered design has the advantage of best utilizing workers' capabilities. Accordingly, ergonomics-focused workplace designs have greater usability, maintainability, and operational safety for blue-collar workers (Hendrick 2003).

Despite the importance of ergonomic warehousing practices, occupational health and safety practices remain one of the least investigated fields in sustainable logistics and supply chain management (Gruchmann et al. 2019b). Compared to sustainable transportation, sustainable warehousing is a relatively small field in sustainable operations management (Mejías et al. 2016), while other areas, such as engineering, quality, and safety management, have addressed related issues more frequently. Moreover, thus far, the focus within sustainable warehousing has mainly been on environmental issues, such as the proper storing of hazardous materials (proper labeling and documentation) or (forklift) training to transport material safely (Ciliberti et al. 2008). From a wider economic and social perspective, the advantages of health and ergonomics projects are personnel benefits (e.g., reduced skill requirements or reduced absenteeism) and material and equipment benefits (e.g., reduced scrap or reduced maintenance), as well as less tangible positive effects (e.g., increased employee commitment or improved corporate image) (Hendrick 2003). In addition, health and ergonomic interventions are supposed to reduce injury risks and the chance of suffering from MSDs (Lavender et al. 2010). In the logistics context, related automation and ergonomics designs are supposed to reduce weights and distances when employees handle heavy products as well as support correct handling movements (Lavender et al. 2010). Table 1 gives an overview of the main health and safety routines and related practices as derived from the literature.

\subsection{Paradox perspective on corporate sustainability tensions}

Organizations and their managers often face complex dynamics and competing demands when engaging in sustainable practices (Schad and Bansal 2018). These can range from diverging short-term and long-term goals (Slawinski and Bansal 2012), the need to reconcile varying stakeholder and organizational interests, both on different levels of analysis and within various contexts (Smith and Tracey 2016; Carollo 
Table 1 Health and safety routines and related practices

\begin{tabular}{|c|c|}
\hline Routines & Related practices \\
\hline Management commitment & $\begin{array}{l}\text { Management commitment to automation and ergonomics projects } \\
\text { increases the probability of successful implementation as this is often } \\
\text { related to the commitment of resources being assigned to these projects } \\
\text { (Hendrick 2003; Yazdani et al. 2018) }\end{array}$ \\
\hline Process orientation & $\begin{array}{l}\text { Process orientation and the notion of continuous improvement support a } \\
\text { clear improvement trajectory with an automation and ergonomics focus } \\
\text { (Shevchenko et al. 2018) }\end{array}$ \\
\hline Accountability & $\begin{array}{l}\text { Operational workers and managers are held accountable for complying } \\
\text { with health and safety rules, as well as measured and rewarded for } \\
\text { working safely (Shevchenko et al. 2018; Yazdani et al. 2018) }\end{array}$ \\
\hline Leadership and expertise & $\begin{array}{l}\text { Ergonomics interventions require knowledge of related (automation) } \\
\text { technologies and their implementation (Hendrick 2003). In addition, } \\
\text { (leadership) capabilities and an aligned human resource management } \\
\text { strategy (e.g., in the form of training) are very relevant for effective and } \\
\text { adequate implementation (Shevchenko et al. 2018) }\end{array}$ \\
\hline Employee involvement & $\begin{array}{l}\text { Successful implementation projects also utilize the experience of } \\
\text { operational workers in a participatory process where a professional } \\
\text { ergonomist serves as a facilitator. Obvious deficiencies that have } \\
\text { relatively inexpensive improvements can lead to quick payoffs and more } \\
\text { acceptance among team members ("simple solutions first") (Hendrick } \\
\text { 2003; Yazdani et al. 2018) }\end{array}$ \\
\hline
\end{tabular}

and Guerci 2018), and in general, the recurring choice between profit and social or environmental issues (Epstein et al. 2015). Such tensions are recognized as an inherent part of sustainability and organizational processes (Smith and Lewis 2011; Hahn et al. 2015). Tensions thereby arise from elements or propositions that individually are logical and desirable, but contradictory and incompatible in combination. A tension can hence be defined as "two phenomena in a dynamic relationship that involves both competition and complementarity" (English 2001, p. 59). The paradox perspective on tensions adds an aspect of persistence to this definition and recognizes paradoxical tensions as "two sides of the same coin" (Lewis 2000, p. 761).

In OSCM, contradictions are traditionally acknowledged as trade-offs (Sandberg 2017), addressing the existing, inherent conflicts by prioritizing certain sustainability goals. While early research on sustainability in OSCM investigated transportation logistics issues through a win-win and/or trade-off lens between economic and environmental/social sustainability (e.g., Brix-Asala et al. 2016), recently researchers tackled sustainability issues in logistics from a paradox theoretical perspective (Pålsson and Sandberg 2019). While the term trade-off in OSCM research is often treated synonymously with the term tension in organizational research (Sandberg 2017), a trade-off implies a different approach to solving the contradiction, namely by choosing one element over the other (Van der Byl and Slawinski 2015). As part of a paradoxical tension, the diverging poles are interrelated and persistent over time, such that a forced decision between the two poles is only temporary, and the tensions will reappear eventually (Smith and Lewis 2011). Unlike the traditional problem-solving rationale of the contingency approach, which is driven by an "either/or" or "if/then" mentality, 
paradox theory applies a "both/and" mentality and focuses on coexistence (Lewis and Smith 2014; Wannags and Gold 2020).

Building on extant research, Smith and Lewis (2011) developed a typology of organizational tensions, distinguishing between the categories of learning, belonging, organizing, and performing, as well as their respective combinations (see Table 2). Learning paradoxes relate to the transformation process in terms of the past to the future and reflect diverging temporal perspectives (e.g., short-term vs. long-term perspectives). Belonging entails those tensions that arise between diverging interests and the identities of stakeholders in relation to each other and the organization (e.g., individual vs. organizational interests). Organizing paradoxes stem from diverging internal dynamics, such as competing processes or incentives (e.g., control vs. flexibility). Performing paradoxes emerge based on contrasting performance expectations, for example, those from diverging internal and external goal setting.

A further systematic framework for classifying tensions in the context of corporate sustainability was proposed by Hahn et al. (2015), going beyond organizational management and considering the larger systemic context. Starting with tensions between social, financial, and ecological issues, which intersect with all other dimensions, the authors identified that tensions can arise between different levels of analysis (i.e., individual level, firm level, systemic level), within temporal or spatial contexts or as a part of the change process related to the implementation of sustainable practices. Table 2 relates this framework to the theoretical underpinnings by Smith and Lewis (2011), which will be the focus of the later analysis. To identify, analyze, and understand the inherent sustainability tensions in the context of warehousing, the present study builds upon these two seminal frameworks on tensions from organizational and sustainability research.

\section{Research design}

Based on the aim of the study of deepening the understanding of sustainability tensions in warehousing logistics, a mixed-methods approach was used. Our research, accordingly, triangulates the qualitative findings of a multiple case study by means of an AHP survey. This cross-validation was pursued between intra-organizational levels and functions to enhance the validity of the observed tensions (Voss et al. 2002). This implied that potential paradoxical tensions were assessed from several perspectives, namely, the logistics and human resource managers' perspectives and the blue-collar employees' perspectives, to analyze interrelated demands regarding ergonomics and automation projects. Finally, the theoretical categories of sustainable warehousinglogistics tensions were aggregated following the theory building approach as proposed by Gioia et al. (2013).

\subsection{Multiple case study through semi-structured interviews}

Case studies are particularly well suited for complex structures as such studies allow intense interaction with the informant and draw on multiple sources of information, 
Table 2 Categorization of organizational sustainability tensions

Organizational tensions based on the framework by Smith and Lewis (2011)

\section{Learning}

Learning/organizing

Learning/performing

Belonging

Belonging/learning

Belonging/organizing

Organizing

Organizing/performing

Performing

Performing/belonging
Tensions between (building upon or destroying) existing and novel activities during processes of renewal, change, and innovation

Tensions between clear routines, which cause stability and efficiency, and the desire to enable dynamic, flexible, agile outcomes

Tension between development of future capabilities while ensuring success in the present

Tensions around individual and collective identities and between different values and roles

Tension between the need for adaption and the individual desire to retain

Tensions between the individual and the collective; individuality vs. collective action

Tensions regarding collaboration and competition, empowerment and direction, flexibility and control

Tensions between means and ends; employee vs. customer demands, high commitment vs. high performance

Tensions around the plurality of competing organizational performance goals in the face of divergent stakeholder demands

Tension between identification and goals; actors negotiate their individual identities with social and occupational demands
Organizational tensions related to the framework by Hahn et al. (2015)

Change, isomorphism vs. structural change

Change

Change within a temporal context

Level, individual vs. organizational

Change within a level context

Level, individual vs. organizational or systemic

Level, organizational vs. supply chain

Level, organizational vs. stakeholder

Level, organizational vs. stakeholder

Level, individual vs. organizational 
Table 3 Cases

\begin{tabular}{|c|c|c|}
\hline Case company & Description & Respondents \\
\hline (1) Logistics service provider A & $\begin{array}{l}\text { Logistics service provider A } \\
\text { operates a warehouse, where } \\
\text { order picking and co- and } \\
\text { repacking activities for the } \\
\text { consumer goods industry are } \\
\text { carried out manually to a } \\
\text { large extent }\end{array}$ & $\begin{array}{l}\text { Warehouse Manager [1], Head } \\
\text { of Sales and Customer } \\
\text { Services [2], Human } \\
\text { Resource Manager [3] }\end{array}$ \\
\hline (2) Logistics service provider B & $\begin{array}{l}\text { At logistics service provider B's } \\
\text { site, co- and repacking } \\
\text { processes as well as display } \\
\text { construction as a value-added } \\
\text { service (VAS) take place for } \\
\text { the consumer goods industry }\end{array}$ & $\begin{array}{l}\text { Process and Project Manager } \\
\text { [4], Area Manager VAS [5], } \\
\text { Human Resource Manager [6] }\end{array}$ \\
\hline $\begin{array}{l}\text { (3) Manufacturer's warehouse } \\
\text { site C }\end{array}$ & $\begin{array}{l}\text { Warehouse sites C and D } \\
\text { belong to a medium-sized } \\
\text { manufacturing company with }\end{array}$ & $\begin{array}{l}\text { Warehouse Manager site C [7], } \\
\text { Shift Supervisor [8], Human } \\
\text { Resource Manager [9] }\end{array}$ \\
\hline $\begin{array}{l}\text { (4) Manufacturer's warehouse } \\
\text { site D }\end{array}$ & $\begin{array}{l}\text { extensive experience in } \\
\text { outbound production } \\
\text { logistics. The company } \\
\text { manufactures products for } \\
\text { industrial applications and } \\
\text { building fasteners (e.g., } \\
\text { screws and dowels). In } \\
\text { Europe, numerous } \\
\text { distribution centers ensure the } \\
\text { fast availability of the } \\
\text { products }\end{array}$ & $\begin{array}{l}\text { Warehouse Manager site D } \\
\text { [10], Shift Supervisor [11], } \\
\text { Human Resource Manager } \\
\text { [12] }\end{array}$ \\
\hline
\end{tabular}

leading to rich and robust data (Eisenhardt and Graebner 2007; Yin 2009). Case study research has developed into an established research design for operations management and has often been implemented through a combined within- and cross-case analysis (Stuart et al. 2002). Eisenhardt (1989) advocates the use of case studies to build and refine theory in so far under-conceptualized areas, which is the case for sustainable warehousing. In order to pursue our research objective of exploring paradoxical tensions in warehousing logistics, cases were selected based on their ability to generate new insights that would help in the development of related theory (Eisenhardt 1989). In line with a theoretical sampling procedure, polar types of automation levels were chosen: two logistics service provider warehouses, $\mathrm{A}$ and $\mathrm{B}$, with rather low automation levels and two industrial manufacturer warehouse sites, $C$ and $D$, with rather high automation levels. Thus, four warehouse locations were sampled to compare within and across industries (consumer goods industry and construction/automotive industry), which is in line with Eisenhardt's (1989) guidelines on a sufficient case study sample size. Table 3 gives an overview of the cases and interview respondents.

Data collection In sum, 12 qualitative interviews were conducted with key respondents in automation and ergonomics, based on an interview topic guide (see the Appendix). The interview guide was sent to the interviewees in advance so that they 
Table 4 Coding scheme

\begin{tabular}{|c|c|}
\hline Coding categories & Description \\
\hline Strain perception (health) & $\begin{array}{l}\text { Issues might arise from the perception of strain during certain } \\
\text { operations. In this line, Berkhout et al. (2004) already investigated } \\
\text { how different work setups affected the mechanical workload and } \\
\text { the subjective evaluation of strain and productivity, confirming the } \\
\text { importance of adjustable work tools that recognize the needs of } \\
\text { the individual }\end{array}$ \\
\hline Acceptance (employee, internal) & $\begin{array}{l}\text { Issues might arise from the retention of employees in change } \\
\text { processes. Previous studies with regard to lean implementation, } \\
\text { for instance, found that a positive employee perception with } \\
\text { regard to the change process is affected by commitment, the work } \\
\text { method, beliefs, and communication (Losonci et al. 2011) }\end{array}$ \\
\hline Versatility (customer, external) & $\begin{array}{l}\text { Issues might arise from external flexibility requirements being } \\
\text { imposed on the operational warehouse processes. In particular, } \\
\text { external changes affect the interaction between employees and the } \\
\text { infrastructure demand for individual capabilities in daily work } \\
\text { routines to achieve less burdening work (Hummel et al. 2015) }\end{array}$ \\
\hline Efficiency (productivity) & $\begin{array}{l}\text { Issues might arise from efficiency-related stressors due to high } \\
\text { productivity requirements. In this vein, Maier et al. (2015) found } \\
\text { that work exhaustion negatively impacts job satisfaction and the } \\
\text { organizational commitment of employees }\end{array}$ \\
\hline Process (technology) & $\begin{array}{l}\text { Issues might arise from technology-related stressors in daily work } \\
\text { life. Previous studies already showed that using information } \\
\text { technology (IT), for instance, indirectly caused psychological and } \\
\text { behavioral responses through work exhaustion (Maier et al. 2015) }\end{array}$ \\
\hline
\end{tabular}

could properly prepare (Voss et al. 2002). Interviews were held with logistics and human resource managers at the warehouse sites and lasted between 60 and $90 \mathrm{~min}$. All interviews were tape-recorded and then transcribed in full (Riege 2003). Two people conducted the interviews, with one leading the interview and the other one taking notes independently, contributing to the reliability of the data collection. Additional workshops with the case companies were performed to collect additional data and to mitigate observer biases and increase external validity (cf. Gruchmann et al. 2019a).

Data analysis The transcripts were analyzed using a qualitative content analysis approach (Riege 2003). Following Eisenhardt's (1989) suggestion of a multi-stage, abductive analytical process, the data across the cases were analyzed deductively using the category system presented in Tables 1 and 2 in the first step, and emerging cross-case patterns were investigated inductively in the second step. Thus, new coding categories were built from the data by coupling the initial codes taken from the literature with constructs that respondents frequently mentioned. Through this iterative process, an emergent, rather than predetermined, coding scheme was finally developed. In a last step, comparisons with extant literature were conducted, as suggested by Riege (2003), to increase the external validity of the conceptualization. The final coding scheme is displayed in Table 4. Finally, for the aim of internal validity, two researchers coded the transcripts and workshop results using the MAXQDA software, thereby successively aligning their mental schemes through continuous discussions of the discrepancies. 
Table 5 Technology alternatives for automation and ergonomic solutions

\begin{tabular}{|c|c|}
\hline Technology alternatives & Examples \\
\hline Ergonomic workstations & $\begin{array}{l}\text { Height-adjustable platforms and worktables, ergonomic } \\
\text { mats, height-adjustable touch screens (e.g., user interface), } \\
\text { daylight-like illumination }\end{array}$ \\
\hline Height adjustment through pallet trucks & $\begin{array}{l}\text { Forklift trucks, scissor lifts, electric pallet truck, chain } \\
\text { conveyors, vacuum lifter }\end{array}$ \\
\hline Exoskeletons & Active exoskeletons, passive exoskeletons, chairless chairs \\
\hline Autonomous transport and picking & $\begin{array}{l}\text { Remote-controlled, height-adjustable vehicles, automated } \\
\text { guided vehicles (AGVs), autonomous, cellular transport } \\
\text { systems, picking robots }\end{array}$ \\
\hline Further assistance technologies & $\begin{array}{l}\text { Handhelds (e.g., scanner), wearables (e.g., hands-free } \\
\text { systems), Pick-by-Light, Pick-by-Voice, Pick-by-Vision } \\
\text { (e.g., augmented reality) }\end{array}$ \\
\hline
\end{tabular}

\subsection{AHP through technology questionnaire}

In recent years, the AHP has increasingly been applied to sustainability-related issues (e.g., Pishchulov et al. 2019). The AHP (Saaty 1986, 2001, 2008) was developed as a performance measurement tool that calculates ratio scales based on discrete and continuous paired comparisons. The method enables decision-makers to consider intangible criteria in the evaluation process by transforming non-material aspects and preferences into numerical values, which can be measured and expressed on a categorical scale. These intangible criteria refer to the individuals' subjective ideas and beliefs that are useful for measuring the performance of a set of alternatives (Saaty 1986, 2008). Hence, participants (e.g., via a survey) compare pairs, each with respect to one criterion from a set of criteria. From these comparisons, taken over all alternatives, priorities result, as well as related rankings. To assess the relevant alternatives for the present study, a general technology screening of automation and ergonomic solutions in warehousing logistics was conducted within an expert workshop with scientific participants from various German universities (cf. Gruchmann et al. 2019a). In particular, (digital) technologies with different levels of machine autonomy were chosen by the workshop participants to investigate the potential transition from an executive role to a supervisory role associated with blue-collar workers (cf. Klumpp and Zijm 2019). Table 5 gives an overview of the technology alternatives that were part of the AHP questionnaire.

Data collection Applying the AHP approach, a questionnaire was developed based on the previous results of the qualitative cases and the expert workshop. Focusing on an ergonomic analysis of the observed processes, the workplace characteristics as well as the individual capabilities of the blue-collar workers served as criteria to assess certain automation and ergonomic technological alternatives (cf. Gruchmann et al. 2019a). The criteria were deduced from the analytic coding categories of the qualitative content analysis approach (see Table 4). While answering the questionnaire, pairwise comparisons of suitable technologies for automation and ergonomic workplace design are expressed as numerical values with the properties of an absolute 
Table 6 AHP ranking

\begin{tabular}{lllll}
\hline Ranking & Coding category & AHP weight $(\%)$ & CI & CR \\
\hline 1 & Strain perception (health) & 33.52 & 0.014262504 & 0.012734378 \\
2 & Acceptance (employee, internal) & 17.98 & 0.030377527 & 0.027122792 \\
3 & Versatility (customer, external) & 16.50 & 0.043209232 & 0.038579671 \\
4 & Efficiency (productivity) & 15.23 & 0.05667127 & 0.050599348 \\
5 & Process (technology) & 16.77 & 0.033085404 & 0.029540539 \\
\hline
\end{tabular}

scale. Preferences for one technology alternative over another with respect to the categories were expressed as the ratio of the value ${ }^{1}$ attached to the item and its alternative (see Eq. 1). A total of 29 blue-collar workers ${ }^{2}$ completed the questionnaire. Details on the socio-demographics of the respondents can be found in the Appendix. It can be seen that most of the workers were male (79\%) and had more than 5 years of work experience (62\%), which is representative of the German logistics sector. Often showing a migrant background and low levels of education, the complex items necessitated extensive instruction during the data collection (approx. 30 min per participant).

Data analysis Applying the AHP procedure, there are $d(m=1, \ldots, M)$ respondents that evaluate the performance of $n(j=1, \ldots, J)$ technology alternatives based on $c(q=1, \ldots, Q)$ criteria. Then, a pairwise decision matrix of each respondent is formulated for the technologies under evaluation based on each criterion (see Table 4) as formulated in Eq. 1 where $p$ represents the performance of a certain technology (see Table 5). From the eigenvectors of the decision matrix associated with the maximum eigenvalue, an arbitrarily picked eigenvector is normed. Values of the corresponding principal eigenvector are global priorities over alternatives on an absolute scale. This means, by ranking the alternatives in descending order, and according to the corresponding values of the principal eigenvector, a ranking of alternatives results from the pairwise comparisons. The consistency of the particular procedure is expressed via a consistency index $(\mathrm{CI})$ and a consistency ratio (CR), the latter being the ratio of the $\mathrm{CI}$ and the random consistency index (RI), which represents an ideal situation when between 0.0 and 0.1 (Saaty and Tran 2007) (see Table 6).

Equation 1 Pairwise decision matrix.

$$
\sum_{m=1}^{M} \sum_{q=1}^{Q} c=\left[\begin{array}{ccccc} 
& j_{1} & j_{2} & \cdots & J \\
j_{1} & 1 & p_{1} / p_{2} & \cdots & p_{1} / p_{J} \\
j_{2} & p_{2} / p_{1} & 1 & \cdots & p_{2} / p_{J} \\
\vdots & \vdots & \vdots & 1 & \vdots \\
J & p_{J} / p_{1} & p_{J} / p_{2} & \cdots & 1
\end{array}\right]
$$

\footnotetext{
1 The value "1" is defined as "very weak," "2" as "weak or slight," and "3" as "moderately important," meaning experience and judgment favor one alternative over another. At the other end of the scale, for instance, " 8 " means "very, very, strong," and "9" means "extremely important".

${ }^{2}$ Generally, AHP studies already yield sensible results with few participants (cf., Whitaker 2007) while smaller samples are quite common in extant literature (e.g., Peterson et al. 1994; Al-Harbi 2001; Pishchulov et al. 2019). It is more decisive for the reliability of the AHP results that the alternatives are defined crisply as well as to assure the homogeneity of the participant group (Schmidt et al. 2016). The present study assured a clear introduction to the process and a common understanding among the respondents.
} 


\subsection{Emergent category building}

In the final analytical stage, the data analysis followed the theory building approach as proposed by Gioia et al. (2013) to aggregate categories of sustainable warehousinglogistics tensions. Based on this approach, we contribute both to conceptualizations of sustainability tensions and to paradox theory per se by empirically exploring relations between the emerging paradoxical tensions from the data (1st order constructs) and by theoretically elaborating on these tensions using preexisting conceptual models from the literature ( 2 nd order constructs). Accordingly, the inductively derived 1 st order constructs were coupled with the theoretical dimensions of the paradox theory to deduce 2 nd order constructs. The evidence that emerged from the data suggested that the observed paradoxical tensions could be aggregated into two main theoretical paradox dimensions of belonging and performing paradoxical tensions, which are most relevant in sustainable warehousing (see Fig. 2).

\section{Ergonomics and automation practices within the cases}

First, we deductively analyzed the health and safety routines and related practices for different intralogistics activities within the four warehouse locations (see Table 1). Qualitative content analyses were conducted within the single cases, which are now described in detail focusing on the human resource and logistics managers' perspectives. The results of the AHP survey are displayed afterwards.

\subsection{Logistics service provider A}

Logistics service provider A sees automation as a potential means to further optimize manual sub-processes with assistive technology and to open up operational areas to a wider range of employees. In this respect, logistics service provider A aims to improve job quality for blue-collar workers because the existing work processes must still be classified as hard physical work. Logistics service provider A has tested assistive technologies in various forms in cooperation with technology providers and uses different kinds of established warehouse equipment (personal protective equipment, forklift trucks, lifting and lowering supported processes, etc.). While the blue-collar workers initially confirmed that the work processes had become (physically) easier, complete acceptance among them was not achieved. For instance, assistive technology solutions were partially rejected. Logistics service provider A particularly fosters employee motivation through occupational change as progressive automation can lead to changes in the professional environment. An example of this is the higher levels of qualifications of industrial employees and the opening up of previously physically demanding jobs to new groups of employees. This is also influenced by a possible improvement of the working environment through modernization due to technical changes, which can also be seen as a benefit aimed at maintaining and increasing employee motivation. In this line, a warehouse manager said: "[...] If you bring this 
process to an ergonomic height. And then ensure that the boxes only have to be pushed or placed in a certain arrangement, [...] that is a great relief, a great help" [1].

\subsection{Logistics service provider B}

Logistics service provider B has tested automation technologies for several logistics applications and uses the technologies on a case-by-case basis, for example, load securing with automated foil sealing. Logistics service provider B has also tested (partial) automation solutions in connection with the automatic assembly and feeding of cartons, such that they do not have to be assembled manually. Although such a solution is technically feasible, many customers did not accept the increased prices for technically more sophisticated cardboard boxes. Generally, logistics service provider B actively involves blue-collar workers in improving the workplace design. To promote health protection, assistive solutions were already implemented (e.g., size-adjustable tables, anti-fatigue mats) that can compensate for differences in size and weight, in keeping with the motto "simple solutions first." Furthermore, logistics service provider B's management has introduced corporate health management, aiming to raise awareness of ergonomic aspects, increase employee motivation, and achieve a better corporate image. Such corporate health management is in place within all the observed companies. A human resource manager confirmed: "Basically, we try from all sides, both the human resources department and the executives, as well as the work council, to take it on board, so that everybody knows what's going on" [6].

\subsection{Manufacturer of warehouse sites C and D}

Because manual activities still dominate individual process steps, the manufacturer operating warehouse sites $\mathrm{C}$ and $\mathrm{D}$ aims to relieve employees from monotonous and physically strenuous activities in the long run with a higher degree of automation. In addition, the manufacturer's principal objective is for them to be able to carry out warehouse activities regardless of gender. Technical elements of process automation have been incorporated and implemented in several projects. For example, a shrinking machine exclusively secures packaging loads. Nevertheless, the manufacturer still sees potential for improvement in manual handling of material and, for example, in the consignment picking of cardboard boxes from pallets. Blue-collar workers continue performing manual tasks, such as assembling products into cardboard boxes, labeling and scanning by hand, and packing boxes onto pallets, because the workers perform these processes more quickly than machines. In this line, the right level of automation is difficult to define. A human resource manager stated: "Assembly or sorting activities are now fully automated with a camera system, which means we do not need personnel anymore. So, these jobs are becoming less and less necessary. In other words, we have more and more difficulties keeping people within their old jobs if they are not qualified enough" [12].

The manufacturer offers safety instructions and training courses on preventing occupational accidents, including training on ergonomic issues. Experienced teams train new employees to pass on specific knowledge about efficient and ergonomically 


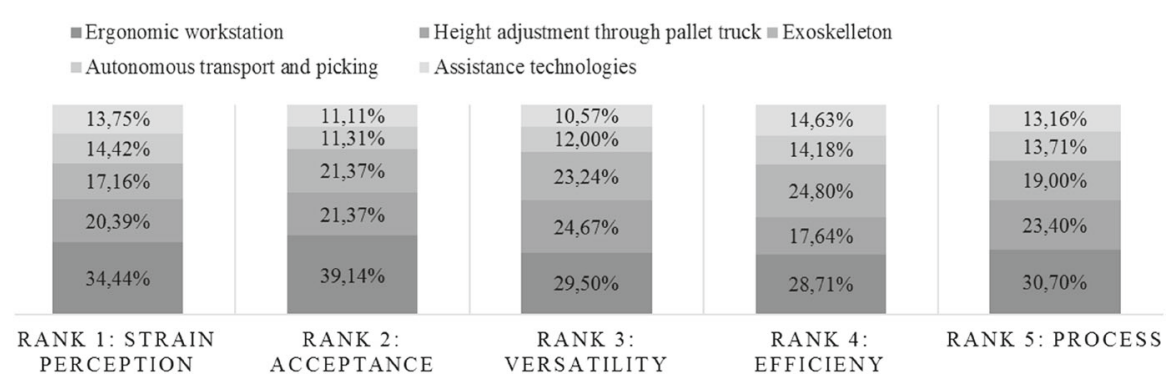

Fig. 1 AHP ranking

enhanced movement sequences. Accordingly, when training new employees, great importance is placed on the safety instructions and ergonomically correct working methods in order to raise employee awareness of these issues right from the start. Regarding the assistive technology involved in lifting and lowering cardboard boxes with cranes, the manufacturer only allows boxes up to a maximum weight limit to be transported manually. Such rules are in place within all the observed warehouse sites of the manufacturer. A warehouse manager said: "In principle, it is the case that we select all possible options [...] employee information, system-based safety routines, and physical safety mechanisms" [7].

\subsection{AHP results}

The findings of the qualitative investigation were informed and triangulated with the blue-collar workers' perspectives through the results of the AHP and the related ranking of desired automation and ergonomics technological alternatives. To reflect the blue-collar workers' perspectives, Table 6 and Fig. 1 depict the results of the AHP ranking that informs the qualitative findings. As a result, the blue-collar workers saw the perception of strain as most relevant for the evaluation of certain workplace designs. In comparison, their acceptance of certain change processes, the versatility of workplace designs, process efficiency, and applied technologies were considered nearly equally in the evaluation of automation and ergonomic projects. With regard to the technology alternatives studied, the blue-collar workers ranked ergonomic workstations as the most relevant. Together with the second ranked item, height adjustment through pallet trucks, these technology alternatives were mostly preferred compared to the other alternatives. Accordingly, in achieving a high level of acceptance among them, height adjustment still plays an important role for the blue-collar workers. In comparison, technologies with a higher automation level, such as AGVs, were ranked rather low.

\section{Paradoxical tensions in sustainable warehousing}

Through analyzing the different perspectives across the observed cases, paradoxical tensions in the implementation and use of automation and ergonomics innovations were explored. Table 7 summarizes the cross-case analysis for the paradoxical ten- 


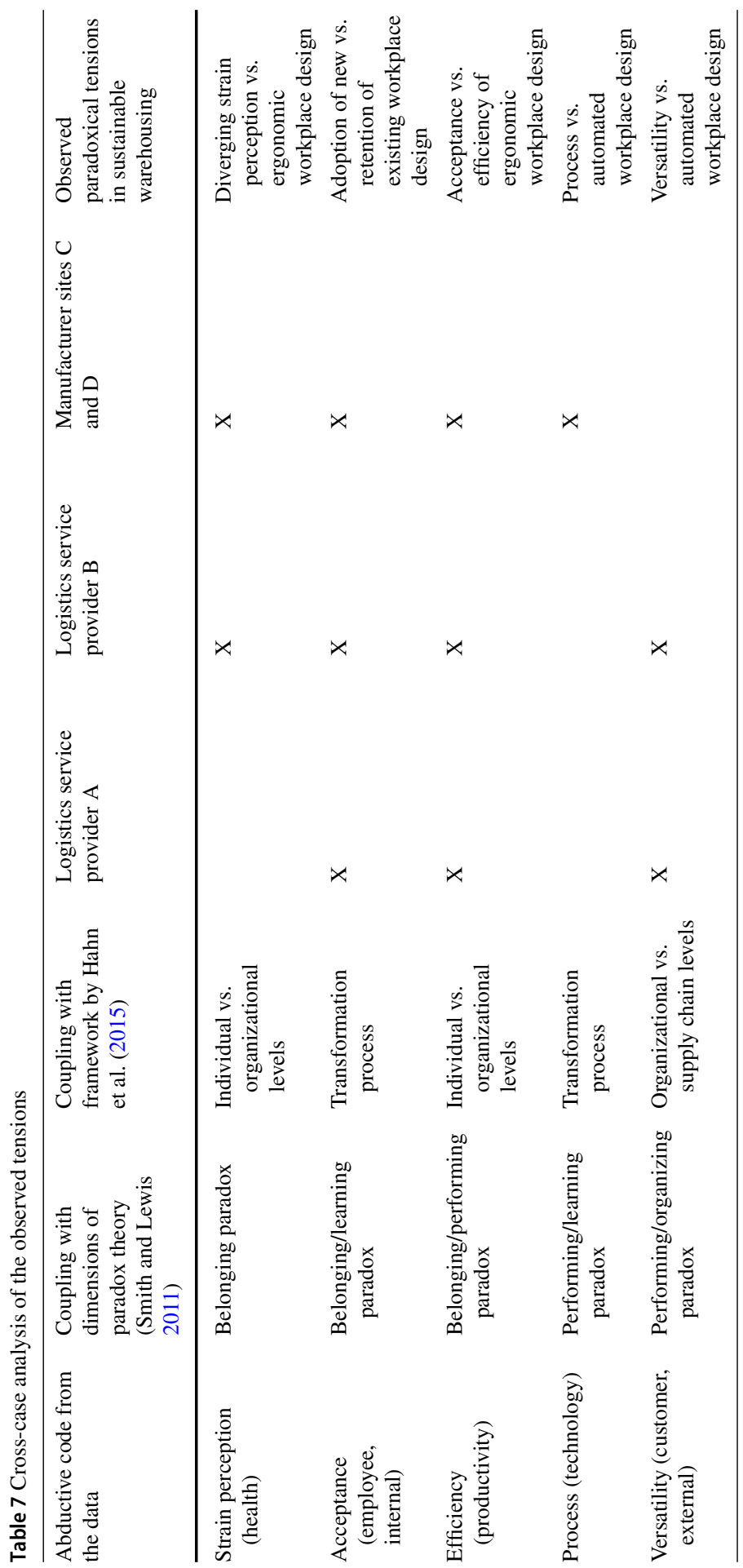




\begin{tabular}{|c|c|c|c|}
\hline 1st order constructs & 2nd order constructs & \multicolumn{2}{|l|}{ Aggregate theoretical dimensions } \\
\hline $\begin{array}{l}\text { Strain perception: Logistics } \\
\text { activities are perceived as } \\
\text { physically strenuous. } \\
\end{array}$ & $\begin{array}{c}\text { Diverging strain perception vs. } \\
\text { ergonomic workplace design } \\
\text { (Belonging paradox) }\end{array}$ & \multirow{3}{*}{$\begin{array}{l}\text { Belonging paradoxes: contradictory } \\
\text { evaluations of the perceived strain as } \\
\text { well as contradictory performance } \\
\text { goals between individual and } \\
\text { organizational levels lead to a low } \\
\text { acceptance during change processes } \\
\text { and, accordingly, blue-collar worker's } \\
\text { retention of existing workplace designs. }\end{array}$} & \multirow{3}{*}{ 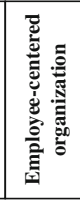 } \\
\hline $\begin{array}{l}\text { Acceptance: The process is } \\
\text { accepted by blue-collar } \\
\text { workers. }\end{array}$ & $\begin{array}{c}\text { Adoption vs. retention of existing } \\
\text { workplace design (Belonging/ } \\
\text { learning paradox) }\end{array}$ & & \\
\hline Efficiency: The process can & Acceptance vs. efficiency of & & \\
\hline efficient $\mathrm{m}$ & (Belonging/performing paradox) & \multirow{3}{*}{$\begin{array}{l}\text { Performing paradoxes: competing } \\
\text { performance goals between company } \\
\text { customer/supply chain levels as well as } \\
\text { insufficient human-machine/ human- } \\
\text { technology interaction hinder technical } \\
\text { automation and improved ergonomic } \\
\text { designs }\end{array}$} & \multirow{3}{*}{ 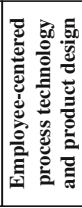 } \\
\hline $\begin{array}{l}\text { Process: The technology used } \\
\text { is adequate for the process } \\
\text { requirements. }\end{array}$ & $\begin{array}{l}\text { Process vs. automated workplace } \\
\text { design (Performing/learning } \\
\text { paradox) }\end{array}$ & & \\
\hline $\begin{array}{l}\text { Versatility: Processes are } \\
\text { flexible to meet customer } \\
\text { requirements. }\end{array}$ & $\begin{array}{c}\text { Versatility vs. automated workplace } \\
\text { design (Performing/organizing } \\
\text { paradox) }\end{array}$ & & \\
\hline
\end{tabular}

Fig. 2 Exploring tensions in sustainable warehousing

sions identified in the cases, while the single categories are described in detail in the following sections. Figure 2 gives a graphical representation of the Gioia approach. To address the observed tension, organizations, process technologies, product designs have to be employee-centered.

\subsection{Tensions between individual and organizational levels (diverging strain perception vs. automation and ergonomic workplace design)}

Regarding the strain perceived while carrying out manual operations, different, contradictory perspectives were observed. From an individual logistics manager's perspective, all manual activities were evaluated as being particularly physically strenuous. Based on this manager's perspective, the division of labor is based on an assessment of the required physical effort, such that physically more strenuous tasks tend to be performed by men, and tasks that require particular dexterity tend to be performed by women. In contrast, from the blue-collar employees' perspective, these activities were seldomly perceived as very strenuous. At logistics service provider B, for instance, employees have reported shoulder and arm pain in individual cases if they construct displays for a long period of time, although the majority of the blue-collar workers did not perceive this activity as very strenuous. Taking into account the results of the AHP, the blue-collar workers most valued alternatives that promote an ergonomic workplace, such as advanced motion sequences. Accordingly, contradictory evaluations of perceived strain exist between the supervisor level and the level of those being supervised, although certain health and safety routines were in place. This belonging paradox represents the tension between the embeddedness of individual and collective identities (Smith and Lewis 2011) in the health and safety context, in which the individuals perceived the manual operations as more taxing than the collective. Therefore, the implications for underlying processes and competencies remain largely underspecified, leading to tensions between individual actions and other organizational levels (Hahn et al. 2015). A respondent accordingly argued: "Stress and strain is different for everyone" [12]. Another human resource manager stated: "There is a loss of information and different interpretations" [9]. 


\subsection{Tensions between adoption of new and retention of existing workplace designs (particularly acceptance vs. efficiency of ergonomic workplace design)}

Within the observed cases, all logistics managers reported a lack of acceptance of new assistive technologies in the long run. Despite the active involvement of the blue-collar workers within the implementation process (for example, in cases $A$ and $D$ ), a positive attitude towards the assistive technologies by blue-collar workers was recorded only in the first few weeks after the solutions were implemented. In this line, a warehouse manager said: "In the beginning, [assistive technologies] were positively evaluated and accepted, but eventually, they were not used anymore" [1]. This tension can also be confirmed by the AHP results, in which the blue-collar respondents ranked assistance technologies the lowest. As an example, the use of pallet trucks and scissor lifts to adjust heights was negatively perceived by the blue-collar workers due to handling reasons, even though logistics service provider A actively involved blue-collar workers during the implementation process and the AHP results indicated that blue-collar workers perceived such equipment generally positively. This example represents a belonging/learning tension between the recognized needs for height adjustment and the individual desire to retain his or her habitual manual handling routines (FallonByrne and Harney 2017). Learning paradoxes are generally evident in such transition processes, particularly when small, incremental changes fall short of addressing the required changes (Hahn et al. 2018). Due to these process discontinuities, the bluecollar employees' attitudes towards introducing additional means of automation, such as autonomous transportation and picking, are also low. Another interviewee said, with respect to this, that the "acceptance among employees of innovations is low. You cannot change everything at once" [3].

Some employees refused to use the technical equipment due to handling reasons and the necessary longer processing time and demanded a return to manual processes. For example, at warehouse site $\mathrm{D}$, attempts have been made to simplify the order picking of cardboard boxes by using new conveyor technology, in which the boxes only have to be pulled down from the conveyor technology and packed onto a pallet. The pallet is placed on a pallet truck to adjust the height. However, upon testing the pallet truck, the manufacturer initially found that employees considered this handling to be too time-consuming as the pallet had to be positioned precisely. This individual rejection, despite the blue-collar workers' actual positive attitudes towards height adjustment, mainly relates to efficiency concerns, indicating a performing/belonging tension originating from unchanged performance targets during change processes. Accordingly, the manufacturer can address this tension by clarifying its stance on the workers' occupational demands, which eventually leads to the acceptance of (slower) height adjustment. Furthermore, the example shows the involvement of a certain temporal context related to the change process (Hahn et al. 2015). A respondent confirmed: "You have to introduce changes slowly not to overburden the employees" [1]. A similar explanation for these tensions was given by a shift supervisor: "Because everything is designed for profit, productivity, and quality, this issue is a bit neglected, although we are still very good. And I would simply wish for or I would hope that my efforts can counteract this a little bit and that I can also focus a little more on people” [11]. 


\subsection{Tensions in technological change processes (process vs. automated workplace design)}

In addition, process-related tensions could be observed in the manufacturer's case, stemming from the use of outdated technologies, as well as capacity bottlenecks. Accordingly, the manufacturer (cases $C$ and $D$ ) still sees potential for improvement in the manual handling of materials and, for example, in the consignment picking of cardboard boxes onto pallets. So far, the blue-collar workers continue performing manual tasks, such as assembling products into cardboard boxes, labeling and scanning by hand, and packing boxes onto pallets, because the workers perform these processes more quickly than machines. Furthermore, the underlying time pressure is amplified by process-related challenges due to capacity bottlenecks and a limited number of channels in the flow rack at the manufacturer's warehouse site $\mathrm{C}$, so that the entire system comes to a standstill when overfilled. In addition, process control in some areas takes place visually, that is, via the manual control of an article with a list in paper form or on a monitor. A shift supervisor stated: "We're still working, very much focused on sight, so they control the items visually using a list or monitor" [8]. Both examples illustrate that efficiency concerns and tensions arising from outdated technologies and capacity bottlenecks reinforce each other and conflict with advanced ergonomic processes and further automation. They hence constitute a learning tension, based on the underlying change process of moving from old to new processes, in combination with performing tensions, derived from performance targets that conflict with demands for enhanced automated workplaces. These tensions can also be confirmed by the AHP results, in which the blue-collar respondents ranked assistance technologies the lowest. Another logistics manager said that "cranes are still rejected. In addition, they do not use the shipping conveyors. It's too slow for them. It's too much technology” [10].

\subsection{Tensions between organizational and customer/supply chain levels (versatility vs. automated workplace design)}

In addition to the tensions between the individual and organizational levels, tensions between the organizational and supply chain levels were reported that hinder a reduction in the product variety and, therefore, the implementation of fully automated solutions (particularly in cases $A$ and $B$ of the logistics service provider). Logistics service provider A, for instance, has fully automated technical solutions that are integrated into the overall process flows at the site and, thus, into their customers' supply chains. However, such systems are usually designed for a specific application and, therefore, cannot be comprehensively replicated for a large variety of products. Logistics service provider A stopped pursuing its goal of full automation in co- and repacking operations. A respondent accordingly stated how "plans [for fully automated solutions] are always rejected because of [the] large variety of article variants that are assembled in various ways and with different packaging schemes" [2]. Here, the service logistic providers are trapped between the tension of organizing and performing, represented by their customers' desire for individual packaging to remain competitive and flexible and (performing), also, by the need to create better working 
conditions with less manual work through automation processes (organizing). Thus, these organizing/performing paradoxes can arise if the company stresses competitive and financial performance purposes. Additional external challenges come from seasonal demand peaks, "with a higher workload and increasing stress for the employees" [3]. Acknowledging the contradictory demands between the customer's wish for process versatility and the possibilities of decreasing manual effort with process standardization, ergonomic alternatives allowing for flexibility, such as exoskeletons, were ranked highly by employees in the AHP. With such solutions, logistics organizations can meet competing demands simultaneously by separating them (Smith and Lewis 2011). In this line, a respondent said: "Warehouse locations are quickly built up and then I say, we have to start, and you have to be very flexible. As a logistics company in the market, that's not easy. It's also a stressful job. This must not be forgotten" [6].

\section{Discussion}

New (digital) technologies provide opportunities for growth and innovation for logistics companies when implemented successfully (Cardona et al. 2013). Accordingly, the main contribution of the present paper is the operationalization of previous theoretical research on paradoxical tensions and its evaluation against empirical data in the warehousing logistics context. This is facilitated by an empirical analysis of four warehousing locations, particularly by elaborating on the question of which tensions exist in the observed cases. Our study revealed that tensions represent a major hurdle for technological change processes, even if ergonomic improvements provide clear advantages for blue-collar workers.

On an individual level, tensions and paradoxes are likely to be created through increased cognitive requirements for blue-collar activities that innovate in warehousing logistics. The risk of such an "artificial divide," which has already been postulated for transportation logistics activities, can also be seen for warehousing logistics (Klumpp and Zijm 2019). In particular, a higher level of machine autonomy will transform related jobs from primarily executive roles to supervisory roles instead (cf. Klumpp and Zijm 2019). Therefore, at the individual level, tensions have to be addressed with a human-centered interaction perspective (Szalma 2009) calling for employee-centered organizations, process technologies, and product designs. The observed tensions include the core underlying different organizational levels and change processes and require the reconfiguration of existing resources, enabling the organization to "reflexively revisit" the processes in a changing environment (Felin and Foss 2009, p. 161). Tensions between human and technological agency, for instance, can be addressed with separation and differentiation strategies, at least regarding disruptive technology transformations, such as artificial intelligence (Klumpp and Zijm 2019). Although the results of the AHP indicate rather strong reluctance regarding higher levels of machine autonomy and automation, such transformations might at least address tensions stemming from the use of outdated technologies, as well as capacity bottlenecks (see the manufacturer's cases).

Considering the empirical findings on an organizational and supply chain level, the observed tensions can be explained through the higher spatial distance between 
warehousing logistics and the customer compared to other logistics functions, such as transportation (cf. Hoejmose et al. 2013). Taking into account the general business context of logistics and its dependence on other supply chain members, fierce competition in the logistics sector (cf. Gruchmann and Seuring 2018) can be seen as another driver of tensions. Particularly, customer pressures with regard to price and flexibility led to labor outsourcing practices at least at one of the case companies. Such labor outsourcing enables companies to keep operations inside their warehouse facilities and, at the same time, flexibly react to changing customer requirements and order volumes (Jaffee and Bensman 2016).

By carving out paradoxical tensions on an individual, organizational, and supply chain level, the present study deepens our understanding of why automation and ergonomic workplace design is not implemented to its potential, even though there is evidence that it would help improving health and safety as well as foster operational performance (Neumann et al. 2006; Das et al. 2008). In this way, we respond to calls for more research on working conditions in supply chains (cf. Carter et al. 2019), and contribute to a more complete picture why intralogistics activities are still characterized by mainly manual tasks (cf. Otto et al. 2017). Furthermore, the concept of tensions may provide a fertile angle for shedding light on other management phenomena featuring contradictory or inconclusive evidence; rather than integrating or synthesizing data and knowledge in the sense of a meta-analysis (e.g., Orlitzky et al. 2003), it provides an intellectual pattern for (re-)assessing inconsistent empirical observations along separate lines, thus facilitating sense-making without forcing uniformity of conclusions.

The present study also responds to Van der Byl and Slawinski's (2015) call for more empirical research addressing sustainability paradoxes by assuming a paradox theory perspective towards tensions in logistics and, specifically, sustainable warehousing. By doing so, the paradox theoretical perspective has highlighted barriers in automation and ergonomic transformational processes, which have previously been addressed solely with a win-win or trade-off lens (cf. Van der Byl and Slawinski 2015). As a result, paradoxical tensions with regard to belonging and performing were examined as the most important, while learning and organizing paradoxes played a minor role in the case companies. Thus, constraints relating to organizational cultures and policies in warehousing create tensions between individual actions and organizational strategies (cf. Hahn et al. 2015). This is also in line with previous research, which particularly sees performing paradoxes as being at the very center of corporate sustainability transitions (Hahn et al. 2018). The explored belonging and performing paradoxes further reflect the importance of the social dimension in sustainable warehousing, which has been mostly neglected in previous research (Gruchmann et al. 2019b). Nonetheless, it can be argued that the varying strain perception and the overall low acceptance of automation and ergonomic change processes may be related to certain learning deficits and tensions in terms of how and why new technologies can be incorporated into daily work routines. Although these know-how related tensions were not as present as others in the cases, it is necessary to build managerial capabilities to encourage behavioral change processes (Fallon-Byrne and Harney 2017). To raise awareness among bluecollar workers regarding the physiological demands of their jobs, communication is seen as a means to change habitual routines. A respondent, nonetheless, said: "The 
communication on the floor or in the warehouse, that's not easy. There are language hurdles, and sometimes we have a high proportion of employees who are not so fluent in German. And, they often do not have a computer. So, we cannot just write an e-mail" [4].

To overcome "the paralysis that decision-makers often experience when confronted with tensions" (Hahn et al. 2018, p. 237), the analysis of the empirical data further allows for informing strategies to manage the observed tensions. Managing tensions derived from the individual employee level and the transformational processes requires advanced strategies to combine them into a more manageable situation (Hahn et al. 2015). Thus, logistics managers may not only try to eliminate or resolve tensions but also try to create a more conducive climate for ergonomic change. This allows for integrative paradox strategies to solve blue-collar workers' tensions. Typical paradoxes discussed in this vein are related to collaboration vs. competition, empowerment vs. direction, and control vs. flexibility (Smith and Lewis 2011; Hahn et al. 2018). These tensions arise from the embeddedness of individual and corporate decisions in the wider organizational context. Accordingly, related strategies for managing these tensions must address the meaning and significance that employees attribute to health and safety practices (Fallon-Byrne and Harney 2017). In this line, Poole and van de Ven (1989) suggest three main strategies for managing paradoxes: (1) The opposition or acceptance strategy focuses on the recognition and persistence of the paradox. This entails keeping the tension open, addressing both poles without emphasizing one over the other or merging them. (2) Spatial or temporal separation divides the paradox through physical segregation or allocation to different levels of analysis or by focusing on the conflicting goals in separated periods. (3) Synthesis strategy introduces an additional, merging element that helps to connect the diverging goals. All the three main strategies are briefly discussed in the following paragraphs, taking into account findings from other disciplines, such as human resource management (HRM), to influence employee climate perceptions by symbolically framing and communicating values and behaviors.

In the context of sustainable warehousing, acceptance strategies must address contextual and boundary conditions (internal and external) in automation and ergonomics projects (Fallon-Byrne and Harney 2017). Acceptance strategies for managing tensions would have to address the impact of this on organizational-level outcomes (see the logistics service provider $B$ and manufacturer cases $C$ and $D$ ). The cases provided evidence that partial automation, in contrast to full automation, should be favored for improving working conditions in warehouse professions, favoring customer demands over automation processes, which also seems to be in favor of the employee's desire to retain the old habits. The tension related to the organizational desire for innovation and securing future capabilities, thereby, remains open and might 1 day resurface. In addition, the cases advise advanced communication to overcome language and cultural barriers.

Separation strategies for managing tensions draw upon innovation and knowledge management (Bellingkrodt and Wallenburg 2013) while potentially prioritizing manual procedures over automated solutions. Accordingly, logistics managers have to enable organizational learning (Felin and Foss 2009) and organizational interventions in the form of communication and consultation (Fallon-Byrne and Harney 2017), 
as well as employee empowerment (Subramony 2009). Thus far, "the employees see within change a negative consequence for themselves. They fear losing their jobs" [6]. To manage these performing paradoxes in particular, related strategies for corporate change must shape expectations within the organization regarding lowering efficiency expectations when implementing new technologies (Hahn et al. 2015), which also can be seen in the observed cases. In this line, the cases point to a (re-)evaluation of assistive technologies from a cognitive ergonomics perspective, as they were ranked the lowest in the AHP. Accordingly, change processes must respect not only physical efficiency but also cognitive personal demands.

Considering a synthesis strategy, several authors have also emphasized the role of leadership skills focused on higher order thinking and expertise, abstraction, and cognitive variety (Helfat and Winter 2011). In this approach, logistics and human resource managers have to address the meaning and significance of employees' contributions to automation and ergonomics innovations. Creating a positive climate in this setting can influence employee perceptions, behaviors, and values to integrate existing disparities, such as gender disparities (Mossholder et al. 2011). Regarding such an implementation strategy, transformation processes must bridge the intended strategy and the enacted strategy through a better understanding of the tensions when striving for corporate sustainability (Fallon-Byrne and Harney 2017), emphasizing the role of routines, path dependencies, and organizational learning. In particular, and in light of the increasing difficulty in recruiting personnel in logistics professions, such strategies might help to innovate current workplaces for them to remain/become attractive employers and combat the development that "only a few employees are available in the job market" [3].

\section{Conclusion and outlook}

This study has explored sustainability tensions in warehousing logistics based on paradox theory. It provides evidence that partial automation and ergonomic alternatives allowing high process flexibility, such as exoskeletons, are highly relevant for improving working conditions in logistics professions and, simultaneously, have a high acceptance rate among blue-collar workers. However, the implementation of such automation and ergonomic practices must be accompanied by additional transformational actions, particularly to address (social) sustainability tensions internally and externally. Accordingly, the present study contributes to theory and practice by providing an answer to the question of to what extent tensions arise from implementing technical automation and improved ergonomic designs in warehousing logistics.

The current research design features some limitations. While aiming to complete the picture of how logistics service providers can implement sustainable intralogistics practices, it was not possible during the interviews and the AHP survey to extensively consider all warehouse activities. Furthermore, the interviews might have been biased by the interviewees' personal expectations and desires. Another limitation linked to our qualitative research approach is its sample size, which does not allow for any statistical generalization of the findings but only for a certain degree of theoretical abstraction and generalization. Another limitation linked to the AHP approach is that the respon- 
dents work in a sufficiently narrow field which excludes further stakeholder groups. These limitations point to future research directions. First, future research might test the results using survey research with a larger sample size and additional stakeholders. Second, additional in-depth comparisons between different logistics activities, such as transportation and packaging logistics, also in different institutional settings, would enhance the theoretical generalizability of the findings. Third, from a broader theoretical perspective, the fusion of the dynamic capabilities' theoretical lens (cf. Teece et al. 1997; Teece 2007) and the paradox theoretical lens appears to be promising, considering our empirical findings that highlight the role of dynamic capabilities on both individual (manager, blue-collar worker) and organizational levels. Exceeding the scope of the present study, little is known about how dynamic capabilities are created and linked to managerial strategies of dealing with sustainability-related tensions in warehousing logistics (cf. Fallon-Byrne and Harney 2017). In this line, the alignment of sensing, seizing, and transformation capabilities with tension management strategies could be a fruitful avenue for future research.

Acknowledgements The authors would like to express their sincere gratitude to Julian Schneider from UCAM Universidad Católica San Antonio de Murcia, Spain, for supporting the data collection as well as Kristina Nestler from FOM University of Applied Sciences, Essen, for her support in conducting and analyzing the interviews. Furthermore, we would like to thank Thomas Hanke and Matthias Klumpp from FOM University of Applied Sciences, Institute of Logistics and Service Management, Essen, for their guidance as project managers of the ADINA project and for supporting the research activities of this study in general. Open Access funding provided by Projekt DEAL.

Funding A part of the presented results comes from the research project "ADINA" (Project number EFRE0800863). The "ADINA" project is supported by grants from the State of North Rhine-Westphalia using funds from the European Regional Development Fund (ERDF) 2014-2020 "Investments in Growth and Employment". Particularly, the data collection and analysis of this study done by the first and third author was facilitated through this funding. The first and the third author were research assistants at the FOM University of Applied Sciences, Institute of Logistics and Service Management, Essen, and thereby employed through the "ADINA" project. The second and fourth author were not part of this funding and mainly contributed to the theoretical framing of the study.

\section{Compliance with ethical standards}

Conflict of interest The authors declare that they have no conflict of interest.

Open Access This article is licensed under a Creative Commons Attribution 4.0 International License, which permits use, sharing, adaptation, distribution and reproduction in any medium or format, as long as you give appropriate credit to the original author(s) and the source, provide a link to the Creative Commons licence, and indicate if changes were made. The images or other third party material in this article are included in the article's Creative Commons licence, unless indicated otherwise in a credit line to the material. If material is not included in the article's Creative Commons licence and your intended use is not permitted by statutory regulation or exceeds the permitted use, you will need to obtain permission directly from the copyright holder. To view a copy of this licence, visit http://creativecommons.org/licenses/by/4.0/. 


\section{Appendix}

\section{Interview topic guide}

1. Introduction to the study

- Introduction to the study, the study's aims, and the researchers

- Assurance of confidentiality and anonymity

2. About the interviewee

- What is your function within the company, and which tasks are associated with this function?

- Where is this function located in the company?

- Can you tell me something about your career (e.g., seniority, industry affiliation)?

3. Workplace design

- Where are the warehouse activities located in the overall process?

- What are the individual activities and the sequence of activities (including durations)?

- Which tools and equipment are in place (technical, ergonomic, logistical)?

- What have your colleagues complained about in the past?

- How do you assess the process (the quality of the process result)?

- Which working time models or rotation models are used?

- How do you train new workers? Is any advice on ergonomics or health protection provided?

4. Process design

- What is the storing and picking strategy?

- Which packaging is used, and why?

- Are there any automated process steps?

- Are ergonomic devices in use?

- What attempts to improve the workplace have been made in the past?

- Which were successful? Which were not? Please state reasons for the failures.

\section{Socio-demographic AHP}

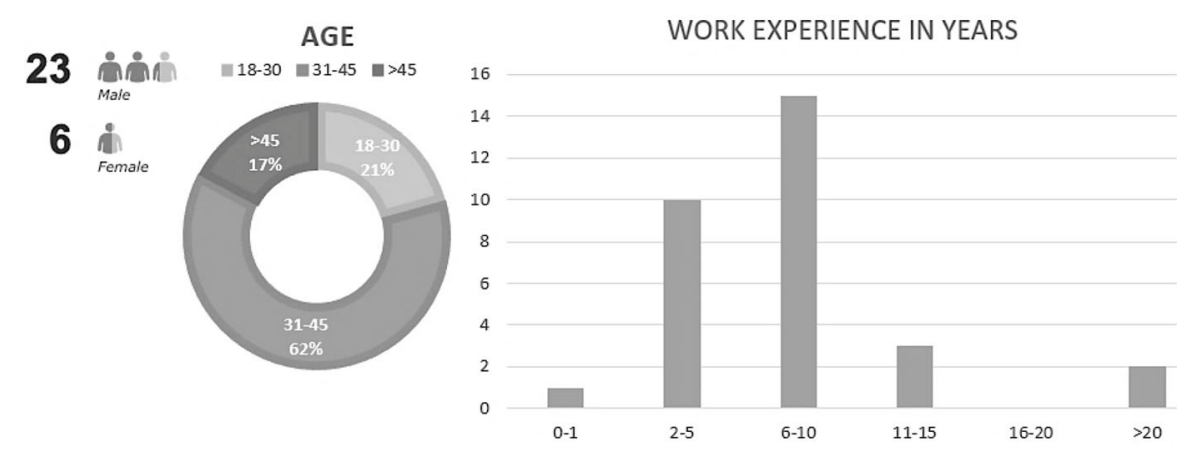




\section{References}

Al-Harbi KMAS (2001) Application of the AHP in project management. Int J Proj Manag 19(1):19-27

Bellingkrodt S, Wallenburg CM (2013) The role of external relationships for LSP innovativeness: a contingency approach. J Bus Log 34(3):209-221

Berkhout AL, Hendriksson-Larsen K, Bongers P (2004) The effect of using a laptopstation compared to using a standard laptop PC on the cervical spine torque, perceived strain and productivity. Appl Ergon 35(2):147-152

Bogataj D, Battini D, Calzavara M, Persona A (2019) The ageing workforce challenge: investments in collaborative robots or contribution to pension schemes, from the multi-echelon perspective. Int $\mathrm{J}$ Prod Econ 210:97-106

Brix-Asala C, Hahn R, Seuring S (2016) Reverse logistics and informal valorisation at the Base of the Pyramid: a case study on sustainability synergies and trade-offs. Eur Manag J 34(4):414-423

Cardona M, Kretschmer T, Strobel T (2013) ICT and productivity: conclusions from the empirical literature. Inf Econ Policy 25(3):109-125

Carollo L, Guerci M (2018) 'Activists in a Suit': paradoxes and metaphors in sustainability managers' identity work. J Bus Ethics 148(2):249-268

Carter CR, Hatton MR, Wu C, Chen X (2019) Sustainable supply chain management: continuing evolution and future directions. Int J Phys Distrib Log Manag 50(1):122-146

Ciliberti F, Pontrandolfo P, Scozzi B (2008) Logistics social responsibility: standard adoption and practices in Italian companies. Int J Prod Econ 113(1):88-106

Conti R, Angelis J, Cooper C, Faragher B, Gill C (2006) The effects of lean production on worker job stress. Int J Oper Prod Manag 26(9):1013-1038

Das A, Pagell M, Behm M, Veltri A (2008) Toward a theory of the linkages between safety and quality. J Oper Manag 26(4):521-535

Eisenhardt KM (1989) Building theories from case study research. Acad Manag Rev 14(4):532-550

Eisenhardt KM, Graebner ME (2007) Theory building from cases: opportunities and challenges. Acad Manag J 50(1):25-32

English T (2001) Tension analysis in international organizations: a tool for breaking down communication barriers. Int J Org Anal 9(1):58-83

Epstein MJ, Buhovac AR, Yuthas K (2015) Managing social, environmental and financial performance simultaneously. Long Range Plan 48(1):35-45

Fallon-Byrne L, Harney B (2017) Microfoundations of dynamic capabilities for innovation: a review and research agenda. Ir J Manag 36(1):21-31

Felin T, Foss NJ (2009) Organizational routines and capabilities: historical drift and a course-correction toward microfoundations. Scand J Manag 25(2):157-167

Gioia DA, Corley KG, Hamilton AL (2013) Seeking qualitative rigor in inductive research: notes on the Gioia methodology. Organizational research methods 16(1):15-31

Grosse EH, Glock CH, Jaber MY, Neumann WP (2015) Incorporating human factors in order picking planning models: framework and research opportunities. Int J Prod Res 53(3):695-717

Gruchmann T, Seuring S (2018) Explaining logistics social responsibility from a dynamic capabilities perspective. Int J Log Manag 29(4):1255-1278

Gruchmann T, Hanke T, Hoene A, Jawale M, Bednorz N (2019a) Aktionsforschung in der Logistik: Erhebungs- und Analyseverfahren für innovative Kommissionier- und Umschlagkonzepte. In: Proff H (ed) Mobilität in Zeiten der Veränderung. Springer Gabler, Wiesbaden, pp 513-525

Gruchmann T, Schmidt I, Lubjuhn S, Seuring S, Bouman M (2019b) Informing logistics social responsibility from a consumer-choice-centered perspective. Int J Log Manag 30(1):96-116

Hahn T, Pinkse J, Preuss L, Figge F (2015) Tensions in corporate sustainability: towards an integrative framework. J Bus Ethics 127(2):297-316

Hahn T, Figge F, Pinkse J, Preuss L (2018) A paradox perspective on corporate sustainability: descriptive, instrumental, and normative aspects. J Bus Ethics 148(2):235-248

Helfat CE, Winter SG (2011) Untangling dynamic and operational capabilities: strategy for the (n) ever-changing world. Strateg Manag J 32(11):1243-1250

Hendrick HW (2003) Determining the cost-benefits of ergonomics projects and factors that lead to their success. Appl Ergon 34:419-427

Hoejmose SU, Grosvold J, Millington A (2013) Socially responsible supply chains: power asymmetries and joint dependence. Supply Chain Manag Int J 18(3):277-291 
Hummel V, Hyra K, Ranz F, Schuhmacher J (2015) Competence development for the holistic design of collaborative work systems in the Logistics Learning Factory. Proc CIRP 32:76-81

Jaffee D, Bensman D (2016) Draying and picking: precarious work and labor action in the logistics sector. WorkingUSA 19(1):57-79

Klumpp M, Zijm H (2019) Logistics innovation and social sustainability: How to prevent an artificial divide in human-computer interaction. J Bus Logistics 40(3):265-278. https://doi.org/10.1111/jbl.12198

Lavender SA, Sommerich CM, Johnson MR, Radin Z (2010) Developing ergonomic interventions to reduce musculoskeletal disorders in grocery distribution centers. In: Proceedings of the Human Factors and Ergonomics Society Annual Meeting, Sage Publications 54(15), Los Angeles, pp 1229-1233

Lewis MW (2000) Exploring paradox: toward a more comprehensive guide. Acad Manag Rev 25(4):760-776

Lewis MW, Smith WK (2014) Paradox as a metatheoretical perspective: sharpening the focus and widening the scope. J Appl Behav Sci 50(2):127-149

Losonci D, Demeter K, Jenei I (2011) Factors influencing employee perceptions in lean transformations. Int J Prod Econ 131(1):30-43

Maas S, Schuster T, Hartmann E (2018) Stakeholder pressures, environmental practice adoption and economic performance in the German third-party logistics industry-a contingency perspective. J Bus Econ 88(2):167-201

Maier C, Laumer S, Eckhardt A (2015) Information technology as daily stressor: pinning down the causes of burnout. J Bus Econ 85(4):349-387

Matthews L, Power D, Touboulic A, Marques L (2016) Building bridges: toward alternative theory of sustainable supply chain management. J Supply Chain Manag 52(1):82-94

Mejías AM, Paz E, Pardo JE (2016) Efficiency and sustainability through the best practices in the Logistics Social Responsibility framework. Int J Oper Prod Manag 36(2):164-199

Mossholder KW, Richardson H, Settoon R (2011) Human resource systems and helping in organisations: a relational perspective. Acad Manag Rev 35(1):33-52

Neumann WP, Winkel J, Medbo L, Magneberg R, Mathiassen SE (2006) Production system design elements influencing productivity and ergonomics: a case study of parallel and serial flow strategies. Int J Oper Prod Manag 26(8):904-923

Orlitzky M, Schmidt FL, Rynes SL (2003) Corporate social and financial performance: a meta-analysis. Org Stud 24(3):403-441

Otto A, Boysen N, Scholl A, Walter R (2017) Ergonomic workplace design in the fast pick area. OR Spectr 39:945-975

Pagell M, Johnston D, Veltri A, Klassen R, Biehl M (2014) Is safe production an oxymoron? Prod Oper Manag 23(7):1161-1175

Pålsson H, Sandberg E (2019) Packed product paradoxes in global supply chains: the case of south African table grapes sold in Europe. In: Proceedings of the 24th International Symposium on Logistics, Würzburg

Peterson DL, Silsbee DG, Schmoldt DL (1994) A case study of resources management planning with multiple objectives and projects. Environ Manag 18(5):729

Pishchulov G, Trautrims A, Chesney T, Gold S, Schwab L (2019) The voting analytic hierarchy process revisited: a revised method with application to sustainable supplier selection. Int J Prod Econ 211:166-179

Poole MS, Van de Ven AH (1989) Using paradox to build management and organization theories. Acad Manag Rev 14(4):562-578

Riege AM (2003) Validity and reliability tests in case study research: a literature review with 'handson' applications for each research phase. Qual Mark Res Int J 6(2):75-86

Saaty TL (1986) Axiomatic Foundation of the Analytic Hierarchy Process. Manage Sci 32(7):841-855

Saaty TL (2001) Decision making for leaders - the analytic hierarchy process for decisions in a complex world. RWS Publications, Pittsburgh

Saaty TL (2008) Decision making with the analytic hierarchy process. Int J Serv Sci 1(1):83-98

Saaty TL, Tran LT (2007) On the invalidity of fuzzifying numerical judgments in the analytic hierarchy process. Math Comput Model 46(7-8):962-975

Sandberg E (2017) Introducing the paradox theory in logistics and SCM research -examples from a global sourcing context. Int J Log Res Appl 20(5):459-474

Schad J, Bansal P (2018) Seeing the forest and the trees: how a systems perspective informs paradox research. J Manag Stud 55(8):1490-1506 
Schaffer S, Kearney E, Voelpel S, Koester R (2012) Managing demographic change and diversity in organizations: how feedback from coworkers moderates the relationship between age and innovative work behavior. J Prod Econ 82(2):45-68

Schmidt K, Babac A, Pauer F, Damm K, von der Schulenburg JM (2016) Measuring patients' priorities using the Analytic Hierarchy Process in comparison with Best-Worst-Scaling and rating cards: methodological aspects and ranking tasks. Health Econ Rev 6(1):50

Schneider E, Irastorza X (2010) Osh in figures: work-related musculoskeletal disorders in the EU. European Agency for Safety and Health at Work, Luxemburg

Schneider J, Gruchmann T, Brauckmann A, Hanke T (2019) Arbeitswelten der Logistik im Wandel: Automatisierungstechnik und Ergonomieunterstützung für eine innovative Arbeitsplatzgestaltung in der Intralogistik. In: Hermeier B, Heupel T, Fichtner-Rosada S (eds) Arbeitswelten der Zukunft. Springer Gabler, Wiesbaden, pp 51-66

Shevchenko A, Pagell M, Johnston D, Veltri A, Robson L (2018) Joint management systems for operations and safety: a routine-based perspective. J Clean Prod 194:635-644

Slawinski N, Bansal P (2012) A matter of time: the temporal perspectives of organizational responses to climate change. Org Stud 33(11):1537-1563

Smith WK, Lewis MW (2011) Toward a theory of paradox: a dynamic equilibrium model of organizing. Acad Manag Rev 36(2):381-403

Smith WK, Tracey P (2016) Institutional complexity and paradox theory: complementarities of competing demands. Strateg Org 14(4):455-466

Stuart I, McCutcheon D, Handfield R, McLachlin R, Samson D (2002) Effective case research in operations management: a process perspective. J Oper Manag 20(5):419-433

Subramony M (2009) A meta-analytical investigation of the relationship between HRM and firm performance. Hum Resour Manag 48(5):745-768

Szalma JL (2009) Individual differences in human-technology interaction: incorporating variation in human characteristics into human factors and ergonomics research and design. Theor Issues Ergon Sci 10(5):381-397

Teece DJ (2007) Explicating dynamic capabilities: the nature and microfoundations of (sustainable) enterprise performance. Strateg Manag J 28(13):1319-1350

Teece DJ, Pisano G, Shuen A (1997) Dynamic capabilities and strategic management. Strateg Manag J 18(7):509-533

Van der Byl CA, Slawinski N (2015) Embracing tensions in corporate sustainability: a review of research from win-wins and trade-offs to paradoxes and beyond. Org Environ 28(1):54-79

Vink P, Koningsveld EAP, Molenbroek JF (2006) Positive outcomes of participatory ergonomics in terms of greater comfort and higher productivity. Appl Ergon 37(4):537-546

Voss C, Tsikriktsis N, Fröhlich M (2002) Case research in operations management. Int J Oper Prod Manag 22(2):195-219

Wannags LL, Gold S (2020) Assessing tensions in corporate sustainability transition: from a review of the literature towards an actor-oriented management approach. J Clean Prod. https://doi.org/10.1016/j. jclepro.2020.121662

Whitaker R (2007) Validation examples of the analytic hierarchy process and analytic network process. Math Comput Model 46(7-8):840-859

Yazdani A, Hilbrecht M, Imbeau D, Bigelow P, Neumann WP, Pagell M, Wells R (2018) Integration of musculoskeletal disorders prevention into management systems: a qualitative study of key informants' perspectives. Saf Sci 104:110-118

Yin RK (2009) Case study research: design and methods. Sage Publications, Thousand Oaks

Publisher's Note Springer Nature remains neutral with regard to jurisdictional claims in published maps and institutional affiliations. 


\section{Affiliations}

Tim Gruchmann $^{1}$ (D) Annika Mies $^{2}$ (D) Thomas Neukirchen $^{3}$ (D) Stefan Gold ${ }^{2}$ (D)

1 Westcoast Institute of Human Resources, Westcoast University of Applied Sciences, Heide, Germany

2 Faculty of Economics and Management, University of Kassel, Kassel, Germany

3 Rhenus Port Logistics Services GmbH \& Co. KG, Duisburg, Germany 